\title{
Control of light environment: A key technique for high-yield and high-quality vegetable production in protected farmland
}

\author{
Xiaoyu Yang ${ }^{1,2}$, Xiufeng Wang ${ }^{1}$, Lijuan Wang ${ }^{3}$, Min Wei ${ }^{1^{*}}$ \\ ${ }^{1}$ College of Horticultural Science and Engineering, Shandong Agricultural University, Taian, China; \\ ${ }^{*}$ Corresponding Author: minwei@sdau.edu.cn \\ ${ }^{2}$ School of Life Sciences, Faculty of Science, The Chinese University of Hong Kong, Hong Kong, China \\ ${ }^{3}$ Department of Horticulture, Tanjin Agricultural College, Tianjin, China
}

Received 22 September 2012; revised 28 October 2012; accepted 10 November 2012

\begin{abstract}
Vegetable crops such as cucumber and tomato are grown widely through the world using not only field but also protected farmland. Sensitive responses of many vegetables have been widely reported to environmental conditions such as light, air temperature, relative humility, and $\mathrm{CO}_{2}$ concentration in the past years. Among these environmental factors, light is considered to be the most important one for vegetable growth and development, especially in protected farmland. Therefore, lots of researches on effects of light environment, including light intensity, light quality, photoperiod, and light direction, on vegetable growth and development have been done in order to optimize the environmental conditions for high-yield and high-quality vegetable production in protected farmland. In this review, recent advances in light environment control for vegetable production in protected farmland have been reviewed and the prospective for the future research has been proposed as well.
\end{abstract}

Keywords: Light Environment; Protected Farmland; Vegetable

\section{INTRODUCTION}

Vegetables are economically important crops and now grown most commonly through the world using not only field culture but also protected-farmland culture. Vegetable crops just like rice, wheat and maize are very sensitive to unfavorable environmental conditions, and the slight stress can influence their growth and yield. So a series of studies on the relationship between environmental factors (e.g. light, air temperature, relative humility and $\mathrm{CO}_{2}$ concentration) and vegetable production have been done in order to optimize the environmental conditions for high-yield and high-quality vegetable production. Among these environmental factors, light is thought to be the most important one for vegetable growth and development, particularly in protected farmland. This review focused on recent advances in the control of light environment, including light intensity, light quality, photoperiod and light direction, for vegetable production in protected farmland. The perspective for future research has also been proposed.

\section{LIGHT INTENSITY}

Light intensity needed for the maximum rate of photosynthesis is quite distinct, depending on vegetable cultivars and ambient conditions. Too low light intensity can not satisfy the requirement of photosynthetic capacity and thus results in insufficient synthesis of photoassimilates, which severely influences vegetable growth, development, and yield. On the contrary, too high light intensity may cause significant decline in the photochemical activity of photosystem II or photosystem I, which is known as photoinhibition [1-4]. It usually occurs when the light-dependent reactions of photosynthesis produce ATP and NADPH in excess of that can be consumed by the reactions of dark carbon metabolism [5, 6]. Healthy leaves growing under favorable conditions can experience intense light without extensive photodamage [7]. However, when the environmental conditions do not promote carbon fixation, even weak or moderate light may become harmful $[8,9]$. For example, weak light can cause severe photoinhibition of cold-sensitive plants when they are exposed to low air temperature [10]. Interestingly, light requirement has been reported for cold-tolerant plants when they suffer from and acclimate clod stress recently [11,12], indicating the strong crosstalk between light and air temperature signal. Supplemental lighting, an important light environment 
control technology widely used in protected farmland, can not only improve light conditions but also result in the increased air and leaf temperature in plant canopy. The increased air and leaf temperature may influence leaf photosynthesis and senescence positively or negatively, depending on seasons. As a result, the efficiency of supplemental lighting fluctuates with seasons because the environmental conditions in protected farmland are more easily controlled at low outdoor temperature in winter [13]. In order to obtain the high-quality vegetable plants under variable light conditions, the photo thermal (PTR) has been proposed [14]. The photo thermal ratio, referring to the ratio of radiant energy (mols of photosynthetic active photons per $\mathrm{m}^{2}$ ) to thermal energy (degree-day), is now thought as a useful tool to identify the optimal balance between light and air temperature [15]. Therefore, finding the optimal PTR for vegetables grown in protected farmland with artificial light maybe improve the efficiency of artificial light.

\section{LIGHT QUALITY}

Light quality is thought to affect many plant physiological processes during growth and development, particularly photosynthesis and morphology. Light quality alters plant photosynthesis by the effects on the activity of photosynthetic apparatus in leaves and the effects on the expression and/or activity of the Calvin cycle enzymes [16]. Cucumbers grown under monochromatic light, including purple, blue, green, yellow and red, have reduced growth, $\mathrm{CO}_{2}$ assimilation rate and quantum yield of photosystem II electron transport as compared with plants grown under white, and these reductions are more significant in the plants under green, yellow and red. Interestingly, plants grown under purple and blue have higher stomatal conductance, total and initial Rubisco activities and higher transcriptional levels of genes encoding key enzymes in the Calvin cycle together with higher total soluble sugars, sucrose and starch contents as compared with plants grown under white, whereas in plants grown under green, yellow and red, these parameters decline. $\mathrm{Yu}$ and Ong [17] reported that the $\mathrm{CO}_{2}$ assimilation rate, dark respiration, total biomass and relative growth rate of seedlings grown under monochromatic radiation were significantly lower than those of seedlings grown under broad spectrum light. Strong ultraviolet-B radiation can cause serious damage to plant photosynthesis, such as losses of both activity and content of Rubisco [18] and sedoheptulose 1,7-biphosphatase [19], inactivation of photosynthetic electron transport chain [19] and induction of stomatal closure [20]. The involvement of light quality in regulation of plant morphology through photoreceptors has been widely studied in the past decades. The phytochromes, an important photoreceptor family including phyA to phyE in Arabidopsis [21-23], can reversibly photoconvert between two conformers: the inactive red light-absorbing $\mathrm{Pr}$ form and the biologically active far red light-absorbing Pfr form. Pr to Pfr photoconversion takes place upon absorption of red light photons, and reversion of Pfr to Pr occurs in far red light-enriched environment and also in the dark [24]. Seedling hypocotyl elongation, which is a common phenomenon and severely decreases seedling commercial quality in seedling production, is just a well-established light-regulated response by phytochromes when seedlings are grown under continuous darkness or far redenriched ambience [25]. Recently, some new findings suggest that plant growth and development might be coregulated by photoreceptors and other endogenous factors such as hormones and temperature sensing system. For example, phytochromes and gibberellins have been reported to act in coordination to regulate multiple aspects of Arabidopsis development such as flowering and hypocotyls elongation [26]. Significant interaction between difference between day/night temperature (DIF) and end-of-day (EOD) light quality on growth, morphology, dry matter content and carbohydrate status has been observed in cucumbers [27]. Positive DIF can induce similar responses in cucumber elongation growth, day matter and carbohydrate accumulation as EOD-farred light, and further phytochrome status can interact with the responses to alternating day and night temperature. Some cases that light quality was involved in plant stress tolerance have also been reported in previous studies. For example, a low red to far red ratio light signal increases CBF (C-repeat/DRE-Binding Factor) expression in Arabidopsis, this increase being sufficient to confer freezing tolerance at temperatures higher than those required for cold acclimation [28]. All these results indicate that it may be essential to choose a suitable light quality for maximizing plant photosynthetic performance, growth and eventually their production when artificial supplemental light is used in protected farmland.

\section{PHOTOPERIOD}

Photoperiod can also influence plant growth and development, especially sex expression. Floral induction and differentiation, the most important developmental transition from vegetative growth to reproductive growth in life cycle of higher plants, can directly affects the agricultural yield through determining the time of flowering, the number of flowers and fruits, as well as the diversion of resources from vegetative growth [29,30]. Longer photoperiod can increase the daily integrated photosynthetic photon flux and more photosynthetic product can thus be synthesized and possibly release the carbohydrate competition between vegetative organs and 
reproductive organs. There have been many reports on effects of photoperiod on sex expression in horticultural crops such as cucumber, a model plant often used for sex expression research in flowering plants [31-33]. The number of pistillate flowers is increased under short photoperiod in monoecious cucumber [34] and in an androecious cucumber [35]. However, Cantliffe [36] reported that photoperiod had no effects on sex expression in cucumber and gherkin. Jutamanee et al. [37] reported that the influence of photoperiod on sex expression depended on the genetic background. The short day treatment promotes pistillate flower formation and suppresses staminate flower formation in monoecious cucumbers due to the increased evolution of endogenous ethylene [31], whereas the long day treatment has the reversed effect [38]. Photoperiod has no significant effects on sex expression in gynoecious cucumbers. Photoperiod can influence leaf senescence as well. Many studies have suggested that leaf senescence occurred as a consequence of shorter photoperiod, whereas extended photoperiod delayed leaf senescence $[39,40]$. This evidence suggests that it is necessary to take both light intensity and photoperiod into consideration as supplemental lighting is applied for crop production in protected farmland. The mean daily light integral (DLI) is thus proposed to evaluate the combined effects of light intensity and photoperiod on plant growth and development when supplemental lighting is used in practice of crops [41-43]. The DLI for optimal plant growth differs considerably between species and canopies [15]. Finding the optimal DLI for horticultural crops grown under different conditions may be an effective way to, on one hand, improve yield and, on the other hand, reduce production cost such as electricity, which is considered to be the greatest one in protected farmland with artificial light.

\section{LIGHT DIRECTION}

Light direction may be involved in regulation of plant growth and development. The ability of leaves to harvest light on different surfaces or from different directions (i.e. direct vs. diffuse rays) is determined by the interplay of structural, biochemical and physiological properties of component cell layers. Depending on azimuth, vertical leaves of plans such as Eryngium yuccifolium and Silphium terebinthinaceum may receive similar daily irradiance on the adaxial and abaxial surfaces and typically have similar photosynthetic rate when irradiated on either surface [44]. These functionally symmetrical leaves of vertical-leaf species are amphistomatous and have unifacial leaf anatomy, with palisade cells beneath the adaxial and abaxial epidermis. In contrast, the light environment of horizontal-leaf species such as Ambrosia trifida and Solidago canadensis is highly asymmetrical, and these leaves typically have photosynthetic rates that are $30 \%-50 \%$ lower when irradiated on the abaxial surface $[44,45]$. These functionally asymmetrical leaves of horizontal-leaf species are anatomically bifacial, with one or more layers of palisade mesophyll beneath the adaxial epidermis and spongy mesophyll beneath the abaxial epidermis. Differential responses of adaxial and abaxial leaf surfaces to light have been attributed to differences in the biochemical characteristics of stomata, palisade and spongy mesophyll cells [46-48]. These differences are similar to the characteristics of sun and shade leaves described by Boardman [49] and Bjorkman [50]. Horizontal leaves irradiated predominantly on the adaxial side during development have chloroplasts in palisade cells with sun-type properties including higher chlorophyll a/b ratio, a lower ratio of appressed to nonappressed thylakoid membranes, and higher electron transport and $\mathrm{CO}_{2}$ fixation rates than found in spongy mesophyll cells [51-53]. When horizontal leaves are irradiated on abaxial side during expansion, sun-leaf and shade-leaf properties become reversed; palisade cells are populated with shade-type chloroplasts and spongy mesophyll cells are populated with sun-type chloroplasts $[52,54]$. As a result, light sensitivity of leaf abaxial side expressed as stomatal conductance is significantly increased [55], indicating that adjustment of light direction might be a feasible way to increase crop canopy photosynthesis and thus improve production.

\section{LOOK TO THE FUTURE}

Now artificial light including top lighting and interlighting has been widely used in protected farmland in the region of high latitude, and as a result, yield of horticultural crops such as tomato and cucumber has increased significantly $[13,15,56]$. However, there are still some issues that should be further studied. For example, undoubtedly supplemental lighting significantly increases vegetable yield, but production cost ramps up at the same time because of the significantly increased electricity consumption. To smooth this problem, several possible methods can be adopted in vegetable production. The first method is to introduce some more efficient artificial light sources such as light-emitting diode (LED) to decrease electricity cost. LED is a semiconductor light source and presents many advantages including lower energy consumption, longer lifetime, improved robustness, smaller size and faster switching, over traditional light sources such as high pressure sodium lamp (HPS) and fluorescent lamps (FL), two kinds of artificial light sources now widely used in protected farmland. Some researches on effects of LED on crop growth and yield have been performed in the past several years [57], but there is still a great gap between the research and the 
application of LED in protected farmland. Therefore, many efforts should be made in the future.

Improving the present lighting design may improve use efficiency of artificial light and decrease electricity cost. Take cucumber as an example, previous studies have shown that interlighting increased cucumber yield and quality more significantly than top lighting due to the more even distribution of artificial light [55]. However, the further increasing of interlight proportion (Top $52 \%$ + Interlight $48 \%$ ), which results in more even distribution of light in cucumber canopy, had only minor effects on the amount of yield and energy use efficiency than the treatment of Top $76 \%+$ Interlight $24 \%$ possibly due to the decrease of artificial light from vertical direction [13]. This evidence indicates that light direction might be optimized. It is well known that light absorbance is severely influenced by incident angle and reaches the maximum when the incident angle is $0^{\circ}$. So light use efficiency may be further improved if light incident angle to vegetable leaves could be adjust to about $0^{\circ}$ through optimizing lighting equipment. Compared with cucumber grown with fluorescent lamps vertically installed, faster fruit growth and higher yield have been observed when cucumbers were grown with fluorescent lamps installed parallelly to cucumber leaves (unpublished data), indicating supplemental lighting based on leaf angle may be feasible.

Besides artificial lighting, improving natural light transmittance and selectivity of cover materials may be a more economic way to improve vegetable production in protected farmland in middle-latitude and low-latitude regions such as East China and Central China because solar light in these regions is enough to support the production of most vegetables. Recently, a new project named as "Study on Environment-friendly Functional Agricultural Film and Related Products", which was supported by National Science and Technology Ministry, has been started in order to develop the new-type agricultural film and related products more suitable for environmental control in the protected farmland of China and is expected to contribute greatly to the modernization of China agriculture.

\section{ACKNOWLEDGEMENTS}

This work has been supported by The National Key Technology R\&D Program of China (2012BAD11B01) and China Agriculture Research System (CARS-25-D-03).

\section{REFERENCES}

[1] García-Plazaola, J.I., Becerril, J.M., Hernández, A., Niinemets, Ü. and Kollist, H. (2004) Acclimation of antioxidant pools to the light environment in a natural forest canopy. New Phytologist, 163, 87-97. doi:10.1111/j.1469-8137.2004.01096.x

[2] Szabo, I., Bergantino, E. and Giacometti, G.M. (2005) Light and oxygenic photosynthesis: Energy dissipation as a protection mechanism against photo-oxidation. EMBO Reports, 6, 629-634. doi:10.1038/sj.embor.7400460

[3] Kreslavski, V.D., Carpentier, R., Klimov, V.V., Murata, N. and Allakhverdiev, C.I. (2007) Molecular mechanism of stress resistance of the photosynthetic apparatus. Biochemistry (Moscow) Supplement Series A: Membrane and Cell Biology, 1, 185-207. doi:10.1134/S1990747807030014

[4] Murata, N., Takahashi, S., Nishiyama, Y. and Allakhverdiev, S.I. (2007) Photoinhibition of photosystem II under environmental stress. Biochimica and Biophysica Acta, 1767, 414-421. doi:10.1016/j.bbabio.2006.11.019

[5] Demmig-Adams, B. and Adams, W.W. (2000) Photosynthesis: Harvesting sunlight safely. Nature, 403, 371-374. doi: $10.1038 / 35000315$

[6] Li, Y.Y., Sperryb, J.S. and Shao, M.G. (2009) Hydraulic conductance and vulnerability to cavitation in corn (Zea mays L.) hybrids of differing drought resistance. Environmental and Experimental Botany, 66, 341-346. doi:10.1016/j.envexpbot.2009.02.001

[7] Govindacharya, S., Bukhovab, N.G., Jolya, D. and Carpentiera, R. (2004) Photosystem II inhibition by moderate light under low temperature in intact leaves of chilling-sensitive and -tolerant plants. Physiologia Plantarum, 121, 322-333. doi:10.1111/j.0031-9317.2004.00305.x

[8] Kudoh, H. and Sonoike, K. (2002) Irreversible damage to photosystem I by chilling in the light: Cause of the degradation of chlorophyll after returning to normal growth temperature. Planta, 215, 541-548. doi:10.1007/s00425-002-0790-9

[9] Gerotto, C., Alboresi, A., Giacometti, G.M., Bassi, R. and Morosinotto, T. (2011) Role of PSBS and LHCSR in Physcomitrella patens acclimation to high light and low temperature. Plant, Cell and Environment, 34, 922-932. doi:10.1111/j.1365-3040.2011.02294.x

[10] Krause, G.H. (1994) Photoinhibition induced by low temperatures. In: Baker, N.R. and Bowyer, J.R., Eds., Photoinhibition of Photosynthesis: From Molecular Mechanisms to the Field, BIOS Scientific Publishers, Oxford.

[11] Kim, H.J., Kim Y.K., Park, J.Y. and Kim, J. (2002) Light signaling mediated by phytochrome plays an important role in cold-induced gene expression through the C-repeat/dehydration responsive element (C/DRE) in Arabidopsis thaliana. Plant Journal, 29, 693-704. doi:10.1046/j.1365-313X.2002.01249.x

[12] Catalá, R., Medina, J. and Salinas, J. (2011) Integration of low temperature and light signaling during cold acclimation response in Arabidopsis. Proceedings of the National Academy of Sciences of the United States of America, 108, 16475-16480. doi:10.1073/pnas.1107161108

[13] Hovi-Pekkanen, T. and Tahvonen, R. (2008) Effects of interlighting on yield and external fruit quality in yearround cultivated cucumber. Scientia Horticulturae, 116, 152-161. doi:10.1016/j.scienta.2007.11.010

[14] Liu, B. and Heins, R.D. (2002) Photothermal ratio affects 
plant quality in "Freedom" poinsettia. Journal of America Society for Horticultural Science, 127, 20-26.

[15] Moe, R., Grimstad, S.O. and Gislerǿd, H.R. (2006) The use of artificial light in year round production of greenhouse crops in Norvey. Acta Horticulturae, 711, 35-42.

[16] Wang, H., Gu, M., Gui, J.X., Shi, K., Zhou, Y.H. and Yu, J.Q. (2009) Effects of light quality on $\mathrm{CO}_{2}$ assimilation, chlorophyll-fluorescence quenching, expression of Calvin cycle genes and carbohydrate accumulation in Cucumis sativus. Journal of Photochemistry and Photobiology B: Biology, 96, 30-37. doi:10.1016/j.jphotobiol.2009.03.010

[17] Yu, H. and Ong, B.L. (2003) Effect of radiation quality on growth and photosynthesis of Acacia mangium seedlings. Photosynthetica, 41, 349-355. doi:10.1023/B:PHOT.0000015458.11643.b2

[18] Allen, D.J., McKee, I.F., Farage, P.K. and Baker, M.R. (1997) Analysis of limitations to $\mathrm{CO}_{2}$ assimilation on exposure of leaves of two Brassica napus cultivars to UV-B. Plant, Cell and Environment, 20, 633-640. doi:10.1111/j.1365-3040.1997.00093.x

[19] Allen, D.J., Nogués, S. and Baker, N.R. (1998) Ozone depletion and increased UV-B radiation: Is there a real threat to photosynthesis? Journal of Experimental Botany, 49, 1775-1788.

[20] Nogués, S. and Baker, N.R. (1995) Evaluation of the role of damage to photosystem II in the inhibition of $\mathrm{CO}_{2}$ assimilation in pea leaves on exposure to UV-B. Plant, Cell and Environment, 18, 781-787. doi:10.1111/j.1365-3040.1995.tb00581.x

[21] Rockwell, N.C., Su, Y.S. and Lagarias, J.C. (2006) Phytochrome structure and signaling mechanisms. Annual Review of Plant Biology, 57, 837-858. doi:10.1146/annurev.arplant.56.032604.144208

[22] Schafer, E. and Nagy, F. (2006) Photomorphogenesis in plants and bacteria. Springer, Dordrecht. doi:10.1007/1-4020-3811-9

[23] Quail, P.H. (2010) Phytochromes. Current Biology, 20, R504-R507. doi:10.1016/j.cub.2010.04.014

[24] Leivar, P., Montec, E., Megan, M., Cohn, M.M. and Quail, P.H. (2012) Phytochrome signaling in green arabidopsis seedlings: Impact assessment of a mutually negative phyB-PIF feedback loop. Molecular Plant, 5, 208-223. doi: $10.1093 / \mathrm{mp} / \mathrm{sss} 031$

[25] Soy, J., Leivar, P., González-Schain, N., Sentandreu, M., Prat, S., Quail, P.H. and Monte, E. (2012) Phytochromeimposed oscillations in PIF3 protein abundance regulate hypocotyl growth under diurnal light/dark conditions in Arabidopsis. Plant Journal, 71, 390-401.

[26] Facella, P., Daddiego, L., Giuliano, G. and Perrotta, G. (2012) Gibberellin and auxin influence the diurnal transcription pattern of photoreceptor genes via CRY1a in tomato. PLOS ONE, 7, e30121. doi:10.1371/journal.pone.0030121

[27] Xiong, J.Q., Patil, G.G., Moe, R. and Torre, S. (2011) Effects of diurnal temperature alternations and light quality on growth, morphogenesis and carbohydrate content of Cucumis sativus L. Scientia Horticulturae, 128, 54-60. doi:10.1016/i.scienta.2010.12.013
[28] Franklin, K.A. and Whitelam, G.C. (2007) Light-quality regulation of freezing tolerance in Arabidopsis thaliana. Nature Genetics, 39, 1410-1413. doi:10.1038/ng.2007.3

[29] Terefe, D. and Tatlioglu, T. (2005) Isolation of a partial sequence of a putative nucleotide sugar epimerase, which may involve in stamen development in cucumber (Cucumis sativus L.). Theoretical and Applied Genomics, 111, 1300-1307. doi:10.1007/s00122-005-0058-4

[30] Chen, H.M., Tian, Y., Lu, X.Y. and Liu, X.H. (2011) The inheritance of two novel subgynoecious genes in cucumber (Cucumis sativus L.). Scientia Horticulturae, 127, 464-467. doi:10.1016/j.scienta.2010.11.004

[31] Yamasaki, S., Fujii, N. and Takahashi, H. (2003) Photoperiodic regulation of CS-ACS2, CS-ACS4 and CS-ERS gene expression contributes to the femaleness of cucumber flowers through diurnal ethylene production under short-day conditions. Plant, Cell and Environment, 26, 537-546. doi:10.1046/j.1365-3040.2003.00984.x

[32] Tanurdzic, M. and Banks, J.A. (2004) Sex-determining mechanisms in land plants. The Plant Cell, 16, S61-S71. doi: $10.1105 /$ tpc. 016667

[33] Miao, M.M., Yang, X.G., Han, X.S. and Wang K.S. (2011) Sugar signaling is involved in the sex expression response of monoecious cucumber to low temperature. Journal of Experimental Botany, 62, 797-804. doi: $10.1093 / \mathrm{jxb} / \mathrm{erq} 315$

[34] Astmon, D. and Galun, E. (1962) Physiology of sex in Cucumis sativus (L.) leaf age patterns and sexual differentiation of floral buds. Annals of Botany, 26, 137-146.

[35] Rudich, J., Baker, L.R., Scott, J.W. and Sell, H.M. (1976) Phenotypic stability and ethylene evolution in androecious cucumber. Journal of the American Society for Horticultural Science, 101, 48-51.

[36] Cantliffe, D.J. (1981) Alteration of sex expression in cucumber due to changes in temperature, light intensity, and photoperiod. Journal of the American Society for Horticultural Science, 106, 133-136.

[37] Jutamanee, K., Saito, T. and Subhadrabandhu, S. (1994) Control of sex expression in cucumber by photoperiod, defoliation, and plant growth regulators. Kasetsart Journal (Natural Science), 28, 626-631.

[38] Wu, T., Qin, Z.W., Zhou, X.Y., Feng, Z. and Du, Y.L. (2010) Transcriptome profile analysis of floral sex determination in cucumber. Journal of Plant Physiology, 167, 905-913. doi:10.1016/j.jplph.2010.02.004

[39] Rosenthal, S.I. and Camm, E.L. (1996) Effects of air temperature, photoperiod and leaf age on foliar senescence of western larch (Larix occidentalis Nutt.) in environmentally controlled chambers. Plant, Cell and Environment, 19, 1057-1065. doi:10.1111/j.1365-3040.1996.tb00212.x

[40] Zhao, H., Li, Y., Duan, B., Korpelainen, H. and Li, C. (2009) Sex-related adaptive responses of Populus cathayana to photoperiod transitions. Plant, Cell and Environment, 32, 1401-1411. doi:10.1111/j.1365-3040.2009.02007.x

[41] Moccaldi, L.A. and Runkle, E.S. (2007) Modeling the effects of temperature and photosynthetic daily light inte- 
gral on growth and flowering of Salvia splendens and Tagetes patula. Journal of the American Society for Horticultural Science, 132, 283-288.

[42] Oh, W., Cheon, I.H., Kim, K.S. and Runkle, E.S. (2009) Photosynthetic daily light integral influences flowering time and crop characteristics of Cyclamen persicum. HortScience, 44, 341-344.

[43] Garland, K.F., Burnett, S.E., Stack, L.B. and Zhang, D.L. (2010) Minimum daily light integral for growing highquality coleus. HortTechnology, 20, 929-933.

[44] DeLucia, E.H., Shenoi, H.D., Naidu, S.L. and Day, T.A. (1991) Photosynthetic symmetry of sun and shade leaves of different orientations. Oecologia, 87, 51-57. doi:10.1007/BF00323779

[45] Terashima I. (1989) Productive structure of a leaf. In: Briggs, W.R., Ed., Plant Biology, Photosynthesis, 8, Alan R. Liss Inc., New York.

[46] Poulson, M.E. and DeLueia, E.H. (1993) Photosynthetic and structural acclimation to light direction in vertical leaves of Silphium terebinthiaaceum. Oecologia, 95, 393400. doi:10.1007/BF00320994

[47] Soares, A.S., Driscoll, S.P., Olmoe, E., Arrabaca, M.C. and Foyer, C.H. (2008) Adaxial/abaxial specification in the regulation of photosynthetic $\mathrm{CO}_{2}$ assimilation with respect to light orientation and growth with $\mathrm{CO}_{2}$ enrichment in Paspalum dilatatum leaves. New Phytologist, 177, 186-198.

[48] Wang, Y., Noguchi, K. and Terashima, I. (2008) Distinct light responses of the adaxial and abaxial stomata in intact leaves of Helianthus annuus L. Plant, Cell and Environment, 31, 1307-1316. doi:10.1111/j.1365-3040.2008.01843.x

[49] Boardman, N.K. (1977) Comparative photosynthesis of sun and shade plants. Annual Review of Plant Physiology, 28, 355-377. doi:10.1146/annurev.pp.28.060177.002035

[50] Bjorkman, O. (1981) Responses to different quantum flux densities. In: Lange, O.L., Nobel, P.S., Osmond, C.B. and
Zeigler, H., Eds., Physiological Plant Ecology I., Ency in Plant Physiology, NS, 12A, Springer, New York. doi:10.1007/978-3-642-68090-8 4

[51] Schreiber, U., Fink, R. and Vidaver, W. (1977) Fluorescence induction in whole leaves: Differentiation between the two teaf sides and adaptation to different light regimes. Planta, 133, 121-129. doi:10.1007/BF00391909

[52] Terashima, I. and Inoue, Y. (1984) Comparative photosynthetic properties of palisade tissue chloroplasts and spongy tissue chloroplasts of Camellia japonica L.: Functional adjustment of the photosynthetic apparatus to light environment within a leaf. Plant and Cell Physiology, 25, 555-563.

[53] Terashima, I. and Takenaka, A. (1986) Organization of photosynthetic system of dorsiventral leaves as adapted to the irradiation from the adaxial side. In: Marcell, R., Clijsters, H. and Van Poucke, M., Eds., Biological Control of Photosynthesis. Martinus Nijhoff, Dordrecht. doi:10.1007/978-94-009-4384-1_20

[54] Terashima, I. (1986) Dorsiventrality in photosynthetic light response curves of a leaf. Journal of Experimental Botany, 37, 399-405. doi:10.1093/jxb/37.3.399

[55] Wang, Y., Noguchi, K. and Terashima, I. (2011) Photosynthesis-dependent and -independent responses of stomata to blue, red and green monochromatic light: Differences between the normally oriented and inverted leaves of sunflower. Plant and Cell Physiology, 52, 479-489. doi:10.1093/pcp/pcr005

[56] Hovi, T., Näkkilä, J. and Tahvonen, R. (2004) Interlighting improves production of year-round cucumber. Scientia Horticulturae, 102, 283-294. doi:10.1016/j.scienta.2004.04.003

[57] Trouwborst, G., Oosterkamp, J., Hogewoning, S.W., Harbinson, J. and van Ieperen, W. (2010) The responses of light interception, photosynthesis and fruit yield of cucumber to LED-lighting within the canopy. Physiologia Plantarum, 138, 289-300. doi:10.1111/j.1399-3054.2009.01333.x 